\title{
Transformation of teacher to teacher leader: Indian scenario
}

\author{
Lavanya Raj \\ Faculty of Education (Educational Leadership), Clayton Campus, Monash University, Victoria, Melbourne \\ Lavanyaraj@education.monash.edu.au
}

\begin{abstract}
The paper discusses the changing roles of teachers, into teacher - leaders in the emerging Indian scenario. It presents teacher leadership model- CIDCONNECT, INFLUENCE, and DEVELOP that can be applied, at various institutes.
\end{abstract}

Keywords: Indian education, teaching, leadership.

\section{Introduction}

Today's major concern of the education sector is for the dearth of quality teachers. The advent of ICT has made a greater spur in the flow of educational information while the new generation of youth is its stakeholders, ready with a power of grasping the less known. There arises the need for the teaching community to equally hone their skill to sew the knowledge gap between the laboratory innovations and to prepare the human resources for future needs. But examining the weakness of knowledge linkage, one hardly hesitates to pose a question- are the teachers prepared to meet the challenge of knowledge transfer at high degree of professionalism and speed? If we have become comfortable with the kind of teachers available for students and schools, then this article is more than a wakeup call. The concept of teacher leadership might not be new to many countries that have put academics on top priority. In India, it remains as nascent concept. But nevertheless, a pressing need, as there is a visible change in Indian education sector due to certain demands and challenges. However as a nation, it is experiencing a metamorphism in education, from a noble profession to a 'business'. The truth is, if the Indian educational system does not come to terms with this global phenomenon- accepting this as a commercial venture or industry and giving back its nobility, it will live in the psychological past. It is time to accept boldly that India is a part of global educational industry and it needs development and professionalism as adopted in other Industrial sectors. This mere change in its ideation will pave way for effective leaderships and leaders to provide what a nation (customer) needs and the world expects.

\section{What is wrong with Indian teachers?}

Roles and responsibilities

- The Directorate of Education (India), Government of NCT of Delhi (2005; No.PS/DE/2005/3383), describes the roles and duties of the teacher. The teacher must, according to the body -

- Attend the morning assembly daily on time.

- Address the students on moral principles, social and environment issues.
- Follow the rules notified in CCS (Conduct) Rules 1964 \& CCS(CCA) Rules 1965

- Maintain the teacher's diary regularly with lesson plan.

- Reach the class on time for teaching.

- The teacher must evaluate the students time to time

- Teachers who are also faculty in-charges will conduct regular meetings and discuss the methods to improve the performance of students in the subject.

What is severely lacking, in the author's perspective, is that the role/duty of a teacher as a leader. It is more of transaction or activity oriented rather than a transformational one. The role does not demand teachers as leaders to students. There is little scope for 'self renewal'. It makes clear here that leadership has not been associated to teaching. It looks as though is, it does and in many ways.

What happens when the role of a teacher is transactional? Let us implore the words Teacher and Student/Pupil. When the word teacher is said, a picture comes to our mind- a picture of a lady/ man with a book and a chalk; either standing near the blackboard or away; sitting in the chair or correcting notebooks. What stands out in this description to me is that, the vividness of the person explaining knowledge that is already present in the book and correcting the reproduction of that knowledge which she/he finds in the notebooks. And what rees a student mean to us? Similar to such conditional Image of an individual, have no say, but only to obey of somebody who is trying to remember knowledge and answer questions. The teacher is a carrier of knowledge, true, but his/her role is to facilitate a process known as learning. We have been conditioned to think of a student as a performer and not as a learner. Thus, this system of cher-student fails. Because the purpose of education is learning, a Teacher Leader has to be a Facilitator in this psychological, intellectual process. The student community needs to transform from passivity to action. Therefore the role of the teacher has to be transformational and less of transactional.

In the Indian context, barring a few private institutions, the roles of the teacher has been restricted to the classroom and mainly to the conventional teaching of 'chalk and talk'. The large area of newer teaching methodologies, assessment methods and facilitating the development of students remain untapped. It is not that Indian teachers do not have the ability to understand or apply, but mainly because these types of educational 
processes are either not understood or simply ignored by the system that is already in place.

\section{Burnout (Shukla, Anil \& Trivedi Tripta, 2008)}

The acquirement of marks and grades put extreme pressures on the teaching community. Abandoning them with no other choice of assessment, the system compels teachers and in turn, teachers compel students. Deadlines to complete syllabus, necessity to stock up revision time, the hard reality of handling 40 and more students per class, being held answerable by administrative authorities and parents for student 'failures' leave our teachers alone, cold, extremely stressed and finally burn out feeling with the insult of professional dissatisfaction.

Teacher leadership (Kurtz, Shelly,2009)

Teacher leadership (TL) can be defined as the process by which a teacher connects the self's goals with the goals of education and intentionally works on four dimensions- individual development, team development, student development and organizational/institutional development. It involves effectively influencing the principal/head master, colleagues, students, parents and other members of the school community. TL includes intentional and sensitive work in the psychological, intellectual and spiritual development of the students. I believe that the Indian education system is now geared for many changes, e.g. newer assessment procedures in the light of Board exams being scrapped by Mr. Kapil Sibal, the Minister of Human Resource Development, India. Whether such policy changes usher for intended reformation is still a debate, certainly it is a move from older methods towards holistic models.

\section{Applicable model for teachers and educators (Fig.1)}

This paper presents teacher leadership model (CID) CONNECT, INFLUENCE, and DEVELOP can be applied, at various intensities for different kinds of schools. There would be higher levels of freedom in private schools to adopt this model. This model also integrates the role of teachers, students, parents and the institution to exert positive changes in educatig! (Fig.2).

\section{Connect}

1. Connect to one's personal goals and vision

2. Connect to the institution's goals and vision

3. Connect to the purpose of education

4. Connect to the students

Influence Principals

1. Influence the principal on applying new

Popular article

COIndian Society for Education and Environment (iSee)

teaching methodologies.

2. Influence the principal on applying new and better assessment procedures.

3. Influence the principal to step up the performance appraisal procedures for the teachers.

4. Influence the principal to create forums where the concerns of students, parents and teachers are discussed in one platform.

5. Influence the principal in creating systems for continuous learning for teachers and assess these learning.

6. Influence the principal for ICT-driven education wherein the redundancy of work is avoided and judicial use of "teacher's skill for the learner's need" is achieved.

\section{Colleagues}

1. Influence fellow teachers in setting up peer learning forums and assess output frequently.

2. Influence fellow teachers to develop strategies to tackle 'burnout' stage: Peer assessment of student's performance, group classes and teaching methodologies $t$ can remove burden of the teachers, collectively.

3. Identifying problems that negatively influence the institution and answering them through specific committees.

4. Reach out to global educational practices and research.

5. Involve in individual and small group research.

\section{Students}

1. Motivate/ inspire students rather than advice.

2. Actively listen to their learning needs and offer suggestions: link them to social needs/ problems to feel for their learning in reality situation: link them to professionals to solve the problems.

3. Engage in two-way learning, i.e. encourage students to teach appropriate lessons.

4. Identify and nurture student leaders who in turn address/coordinate student groups in student related issues - study skills, exam skills, career planning.

\section{Parents}

Influence parents to learn teaching/monitoring methods that can be used at home.

\section{Develop}

Psychological development of students

A teacher leader must pay active attention to the psychological needs of the students. This calls for an understanding of basic psychology and psychology of children and adolescents.

"Teacher leader" http://www.indjst.org
Lavanya Raj Indian J.Sci.Technol. 
Equipping oneself with methods to motivate students and see them through age related issues, academic issues and social issues is important for a teacher to become a leader. A TL is able to understand all the forces that act upon a child's psychological development and is able to guide, motivate and simply facilitate this growth (Diane Sweeny,2003).

\section{Intellectual development}

Although education in itself caters to intellectual development, a TL can contribute and help students who get lost in the system. By rightly, stimulating the minds of students, teachers can begin the process of intellectual development. This can be done in many creative ways, but informal sharing of ideas, philosophies and concepts makes the learning stress free.

\section{Spiritual development}

A student who is connected to the 'purpose' of life does eventually become successful. Although the concept of purpose and success are defined differently, I refer here to a purpose that can make a student/individual useful and contribute to him/her and to the environment and to the self. If a teacher is successful in igniting such a thought and assist the student sail through in understanding the world and how all human behavior is connected, he/she has assisted in their spiritual development as well.

The strength of this model lies in the fact that it emanates from the self, that is, it makes the connection between the teacher's goals and institution's vision. Once such a connection is achieved, leadership becomes successful. Most leaders, who fail, fail because there is no 'buying in mechanism'.

The psychological, intellectual, spiritual development leads to cross-cultural tolerance, facilitating students for global employability.

Teacher leaders should exercise two skills: 'Influence' and 'encourage team work'. The needs of change can vary from institution to institution and culture to culture.
Teacher leaders do not wait for being asked but take up initiatives and drive them. Unless teachers as leaders connect to students it will be mere teaching and there will be less of learning and development.

The holistic nature of the model - The notion of 'development' is perhaps the single most important concept in education. We use other terms to describe development- including growth, progress, learning, and improvement. Regardless of the term we use to describe it, the concept of individual development is the central idea underlying all teaching and learning. Development perhaps is the single most reason for this model, When teachers are left behind, students are also left behind. In a sense, the same holds true to parents also. Working out the practicality of such a model will take courage and persistence. Above this, it will take painstaking logical work in terms of putting in lots of systems together to reap the benefits. If the principals/CEO's of organizations are the first to address issues, then the application of this model can be comparatively easier.

This Holistic development (psycho-spiritualintellectual) will address the much needed cross cultural tolerance \& will upgrade the level of not only learning but also global employability skills of students and teachers. It holds the possibilities of upgrading parental skills in assisting learning and development in their children also.

\section{References}

1. Diane Sweeny (2003) Learning along the way: professional development by and for teachers.

2. Kurtz, Shelly (2009) Teacher leadership. ProQuest Edu. J. 39, 12.

3. Shukla, Anil and Trivedi Tripta (2008) Burnout in Indian teachers. Asia Pacific Edu. Rev. 9, (3),320334.

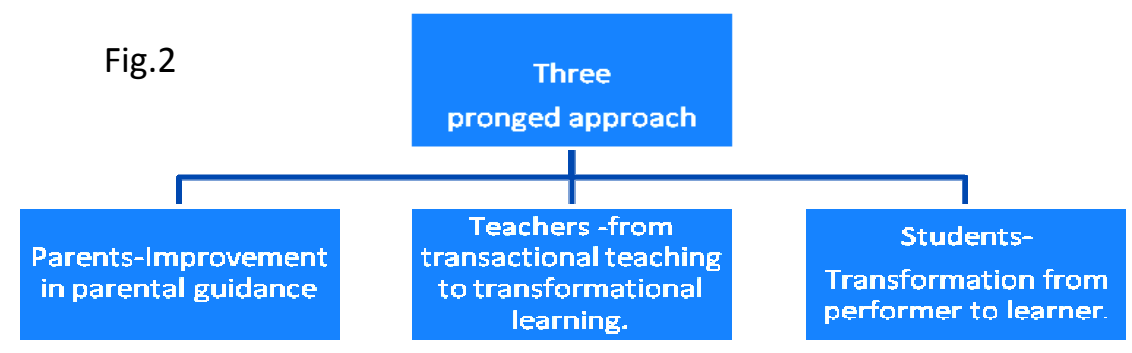

